Provided for non-commercial research and education use. Not for reproduction, distribution or commercial use.

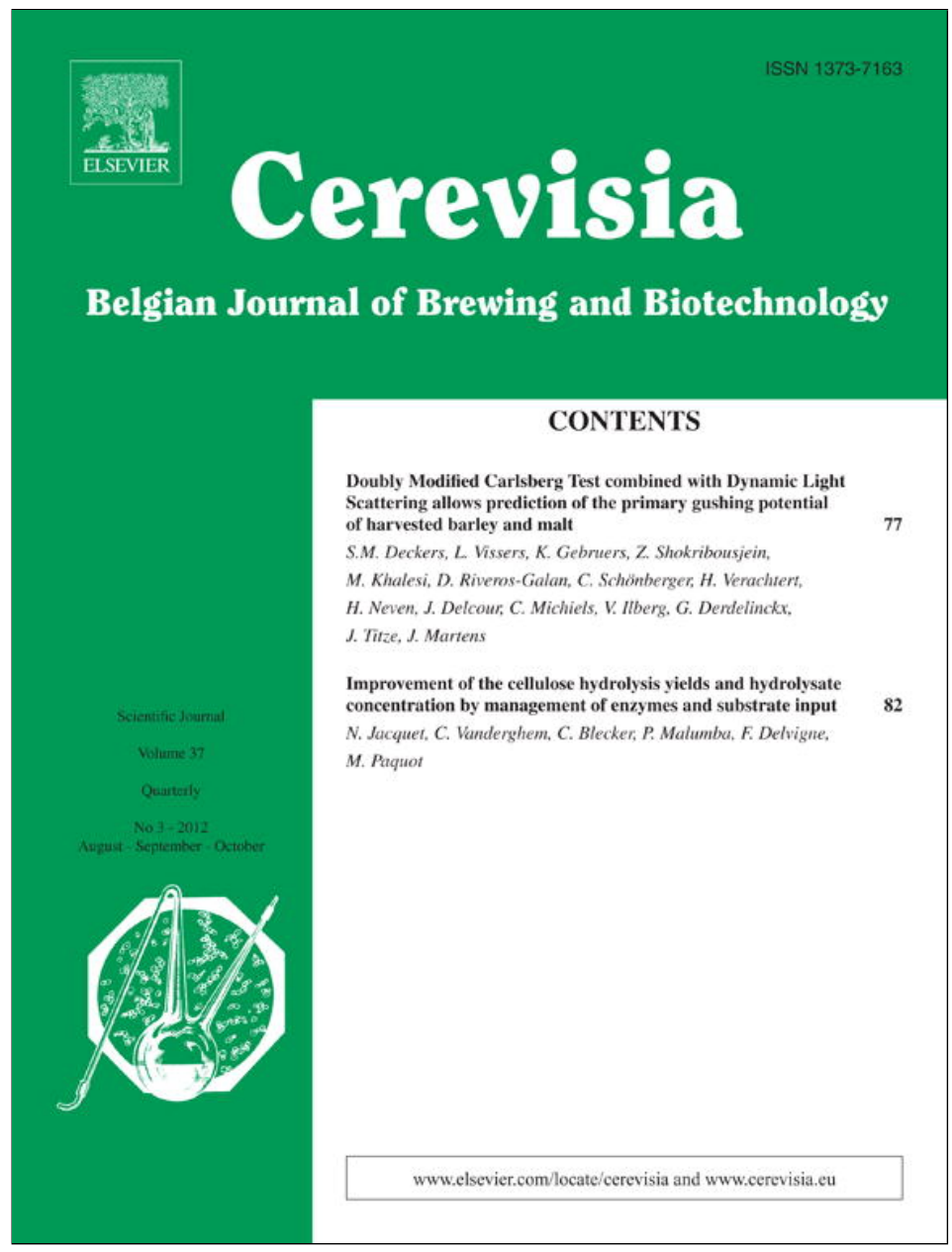

This article appeared in a journal published by Elsevier. The attached copy is furnished to the author for internal non-commercial research and education use, including for instruction at the authors institution and sharing with colleagues.

Other uses, including reproduction and distribution, or selling or licensing copies, or posting to personal, institutional or third party websites are prohibited.

In most cases authors are permitted to post their version of the article (e.g. in Word or Tex form) to their personal website or institutional repository. Authors requiring further information regarding Elsevier's archiving and manuscript policies are encouraged to visit:

http://www.elsevier.com/copyright 


\title{
Doubly Modified Carlsberg Test combined with Dynamic Light Scattering allows prediction of the primary gushing potential of harvested barley and malt
}

\author{
S.M. Deckers ${ }^{\text {a,* }}$, L. Vissers ${ }^{a}$, K. Gebruers $^{a}$, Z. Shokribousjein ${ }^{a}$, M. Khalesi $^{a}$, D. Riveros-Galan ${ }^{a}$, \\ C. Schönberger ${ }^{b}$, H. Verachtert ${ }^{a}$, H. Neven ${ }^{a, c}$, J. Delcour ${ }^{a}$, C. Michiels ${ }^{a}$, V. Ilberg ${ }^{d}$, G. Derdelinckx $^{a}$, \\ J. Titze ${ }^{\mathrm{e}}$, J. Martens ${ }^{\mathrm{f}}$ \\ ${ }^{a}$ KU Leuven, Department of Microbial and Molecular System $\left(M^{2} S\right)$ - LFoRCe-LIBR (Leuven Institute for Beer Research), Kasteelpark Arenberg 33, P.O. Box 2463, BE-3001 Heverlee, \\ Belgium \\ ${ }^{\mathrm{b}}$ Barth-Haas Group, Barth Innovations, Joh. Barth und Sohn, Freiligrathstrasse 7/9, D-90482 Nuremberg, Germany \\ ${ }^{\mathrm{C}}$ Duvel-Moortgat Brewery, Breendonkdorp 58B, BE-2870 Puurs, Belgium \\ ${ }^{\mathrm{d}}$ Hochschule Weihenstephan-Triesdorf, Fakultät Gartenbau und Lebensmitteltechnologie, Am Standengarten 11, D-85350 Freising, Germany \\ e National University of Ireland, University College of Cork, School of Food and Nutritional Sciences, College Road, Cork, Ireland \\ ${ }^{\mathrm{f}}$ KU Leuven, Department of Microbial and Molecular System ( $\mathrm{M}^{2}$ S), Centre for Surface Chemistry and Catalysis, Kasteelpark Arenberg 23, P.O. Box 2461, BE-3001 Heverlee, Belgium
}

\section{A R T I C L E I N F O}

\section{Keywords:}

Hydrophobin

Primary gushing

Dynamic Light Scattering

Nanobubble

Barley

Malt

\begin{abstract}
A B S T R A C T
Despite intensive research on the gushing of carbonated beverages during the last decades, there is no universal method to predict its occurrence and consequently how to avoid the economic losses it induces. Primary gushing can be visualized as the strong overfoaming and/or strong liquid expulsion of liquid when a bottle of carbonated beverage is opened. This process results from the interaction between gaseous $\mathrm{CO}_{2}$ and class II hydrophobins. Both chemicals are present in the pressurized liquid as $\mathrm{CO}_{2}$ nanobubbles coated by hydrophobins which explode when at bottle opening the pressure is released, which results in a vigorous expulsing of $\mathrm{CO}_{2}$. Hydrophobins are produced by filamentous fungi in the field or during storage and processing. To avoid gushing of beers, their early detection in the barley-to-beer chain is of capital importance. To ascertain with more certainty the presence of hydrophobins on barley and malt and their gushing inducing property, the gushing test mostly often used in practice, the doubly Modified Carlsberg Test, was used but it was followed by a new test based on the detection of $\mathrm{CO}_{2}$-hydrophobin nanoparticles by Dynamic Light Scattering (DLS). This allowed to certify that the potential of provoking gushing by samples of barley and malt is due to the potential of provoking a primary gushing and the presence of fungal products: hydrophobins. The results showed also that only $5 \%$ of gushing provoking grains in the grist is sufficient to induce gushing and the detection of the nanoparticles, typical for primary gushing.
\end{abstract}

(C) 2012 the Associations of the Former Students of the Belgian Brewing Schools. Published by Elsevier B.V. All rights reserved.

\section{Introduction}

In 1909, Kastner, a German brewing scientist, was the first to report strong foam and beer overflows after opening "normal" beer bottles without shaking (Kastner, 1909). This phenomenon known as gushing was later observed with other $\mathrm{CO}_{2}$ saturated beverages such as champagne and sparkling wine (Zoecklein, 1999), cider (Wilson et al., 1999), soda and even mineral water (Fischer, 2001) although it seems to be most relevant in beer (Pellaud, 2002) where it represents severe economic losses and bad brand image. In the 1960s, gushing is divided in two types based on the causes. While

\footnotetext{
* Corresponding author.

E-mail address: Sylvie.Deckers@biw.kuleuven.be (S.M. Deckers).
}

secondary gushing is due to technical and technological problems related to the brewing process, primary gushing occurring periodically, is related to the quality of raw material and becomes of more concern for the malster (Pellaud, 2002). In the 1960-1970s, some causes of primary gushing were proposed and a fungal contamination of raw material by molds such as Fusarium sp. was suggested. Molecules involved remained unknown (for a review see Pellaud, 2002). Wessels et al. (1991) discovered an amphiphilic protein produced by filamentous fungi and called it hydrophobins on the base of its amino-acids sequence. In 1996, the hypothesis that organic materials such as proteins produced by molds could form solid pellicles around $\mathrm{CO}_{2}$ gas bubbles is advanced but it was not explained how and why (Gardner, 1973; Casey, 1996). At the end of 1990s hydrophobins were considered as the major contaminants responsible for primary gushing (Haikara et al., 1999) but the mechanism 
still remained unexplained. Despite this knowledge, parts were still missing in the gushing puzzle: how does primary gushing occur and how to prevent it? (Winkelmann and Hinzmann, 2009). These questions remained unanswered due to the fact that people put all emphasis on hydrophobins and not on the true responsible molecule, which is $\mathrm{CO}_{2}$ (Deckers et al., 2011) which can be deduced from the observation that gushing can be reduced by reducing the bottle opening temperature. To understand this phenomenon, it was necessary to study the whole process with consideration of the physico-chemical properties of both hydrophins and $\mathrm{CO}_{2}$. It was important to understand the notion of the critical diameter of a gas bubble, which is ruled by the Young-Laplace and the Henry's law (Nelson, 2009; Deckers et al., 2010). Recently, Deckers et al. (in press) showed by molecular dynamics simulation that $\mathrm{CO}_{2}$ molecules go to interact with the hydrophobic patch of the HFBII hydrophobin and described in successive steps the formation of nanobubbles stabilized by crystalline layer of Class II hydrophobin. These nanobubbles stabilized by hydrophobins and having an internal pressure corresponding to approximately 4 bars will act as nanobombs when the bottle will be opened (i.e. release of the pressure resulting in the detend of the gas) (Deckers et al., 2010, in press).

The economic disastrous effects caused by gushing become more and more apparent and explain why research was intensified in different countries such as Germany and Finland mainly on the development of a method to detect and predict primary gushing. Different methods based on a correlative factor (i.e. do not measure gushing but a factor correlated to gushing) were developed such as standard plate counts for barley or malt infection, ELISA test, PCRbased methods, presence of mycotoxin test, etc. (for more details see Garbe et al., 2009; Shokribousjein et al., 2011). Three "different" more direct tests to detect gushing were also developed. The first one called the Carlsberg test consists in adding a water extract of malt to a bottle of commercial beer and measuring the overflow. In the Modified Carlsberg Test (MCT), the non-standardized beer matrix used in the Carlsberg test is replaced by sparkling water $\left(7 \mathrm{~g} \mathrm{CO}_{2} / \mathrm{L}\right)$. However, an inter-laboratory test underlined the lack of reproductibility of this test, most probably due to many parameters different from laboratory to laboratory (Haikara et al., 2005; Rath, 2008). In the doubly Modified Carlsberg Test $\left(\mathrm{M}^{2} \mathrm{CT}\right)$ fine malt grist was used for the preparation of Congress worts and these worts were added to sparkling water $\left(7 \mathrm{~g} \mathrm{CO}_{2} / \mathrm{L}\right)$ (for more details about the gushing tests, see Garbe et al., 2007, 2009). From these three gushing tests, Garbe et al. (2007) showed that the best way for a reliable prediction of gushing from six malts was to prepare fine grist and congress wort (i.e. using the $\mathrm{M}^{2} \mathrm{CT}$ in place of MCT). In Germany (for a complete review, see Christian et al., 2011) Christian developed new ideas to quantify gushing more precisely because the overfoaming amount for the gushing test can fluctuate. He proposed to determine the minimal volume of a wort needed to induce gushing but also to determine the amount of a $\mathrm{CO}_{2}$ hop extract to inhibit gushing (Christian et al., 2009a, 2010b). He combined also particle size analysis and charge titration test (Christian et al., 2010a). In 2011, a new method based on Dynamic Light Scattering (DLS) was developed to detect primary gushing in final products by the detection of particles with a diameter of approximately $100 \mathrm{~nm}$ in the gushing beverages (Deckers et al., 2011). Dynamic Light Scattering is a method to determine the size distribution profile of small particles undergoing Brownian motion in a solution. A laser provides a light source to illuminate a sample contained in a cell. The small particles cause the intensity to fluctuate more quickly than the large ones as they are moving faster. The scattering intensity signal from the detector is passed to a digital processing board called a correlator which compares the scattering intensity at successive time intervals to derive the rate at which the intensity is varying. The information of the correlator is then analyzed by
Table 1

Composition of the grind.

\begin{tabular}{|c|c|c|c|c|c|c|c|}
\hline \multicolumn{8}{|c|}{ Non-gushing barley - non-gushing malt } \\
\hline NG barley (\%) & 0 & 10 & 20 & 30 & 40 & 50 & n.d. ${ }^{\mathrm{a}}$ \\
\hline NG malt (\%) & 100 & 90 & 80 & 70 & 60 & 50 & n.d. \\
\hline \multicolumn{8}{|c|}{ Gushing barley - non-gushing malt } \\
\hline$\overline{\mathbf{G} \text { barley }}(\%)$ & 0 & 10 & 20 & 30 & 40 & 50 & n.d. \\
\hline $\bar{N} G$ malt (\%) & 100 & 90 & 80 & 70 & 60 & 50 & n.d. \\
\hline \multicolumn{8}{|c|}{ Non-gushing malt - Gushing malt } \\
\hline NG malt (\%) & $10 \overline{0}$ & 90 & 80 & 70 & 60 & 50 & 0 \\
\hline$\underline{\mathbf{G}}$ malt(\%) & 0 & 10 & 20 & 30 & 40 & 50 & 100 \\
\hline \multicolumn{8}{|c|}{$\bar{N}$ on-gushing barley - Gushing malt } \\
\hline NG barley (\%) & 0 & 10 & 20 & 30 & 40 & 50 & n.d. \\
\hline G malt (\%) & 100 & 90 & 80 & 70 & 60 & 50 & n.d. \\
\hline
\end{tabular}

a Not determined.

the machine software and the size information is obtained (Hunter, 2005). The objective of this study was the combination of the $\mathrm{M}^{2} \mathrm{CT}$ and the DLS methods to analyze malt samples but also harvested barley regarding the primary gushing potential and to show how the DLS method gives more certainty about the causes of gushing.

\section{Materials and methods}

\section{Characterization of gushing potential of barley and malt by} doubly Modified Carlsberg Test $\left(M^{2} C T\right)$

A gushing (variety Azurel) and a non-gushing (variety Sebastian) barley samples were kindly provided by the malt house Dingemans (Stabroek, Belgium). Gushing and non-gushing malt samples (variety Prestige) were kindly provided by Cargill (Herent, Belgium). In order to extract hydrophobins from grains, standard laboratory Congress wort was produced according to Analytica-EBC (2004) method 4.5.1. Laboratory-scale mashing experiments were carried out in an automated mashing bath (LB8 Electronic Mashing Bath, Funke Gerber GmbH, Berlin, Germany). The grains were ground in a Bühler-Miag mill (Bühler-Miag, Minneapolis, MN) set for fine grist coarseness ( $0.2 \mathrm{~mm}$ gap between the grinding discs). Fine grind (50.0 g; the composition (in \%) containing gushing and non-gushing grists is given in Table 1) was mixed with $200 \mathrm{~mL}$ of water at $46^{\circ} \mathrm{C}$. A temperature of $45^{\circ} \mathrm{C}$ was maintained in the mash for $30 \mathrm{~min}$. The temperature was then raised at $1^{\circ} \mathrm{C}$ per min to $70^{\circ} \mathrm{C}$ before $100 \mathrm{~mL}$ water $\left(70^{\circ} \mathrm{C}\right)$ were added. The temperature was maintained at $70^{\circ} \mathrm{C}$ for $1 \mathrm{~h}$ before cooling down to room temperature in $10-15 \mathrm{~min}$ $\left(4{ }^{\circ} \mathrm{C}\right.$ per min). The mash was continuously stirred at $100 \mathrm{rpm}$. After adjusting the beaker content to $450 \mathrm{~g}$, the contents were stirred thoroughly and emptied immediately and completely into a filter (filter Macherey-Nagel MN 614 1/4 320 mm diameter, Filter Service S.A., Eupen, Belgium). The first $100 \mathrm{~mL}$ of the filtrate were returned to the funnel. The filtration was stopped when the cake appeared dry and the wort was obtained. Each combination (Table 1) was used at least two times to produce a wort. For each wort obtained, $20 \mathrm{~mL}$ of sparkling water $\left(1 \mathrm{~L}, 7 \mathrm{~g} \mathrm{CO}_{2} / \mathrm{L}, 2^{\circ} \mathrm{C}\right)$ were replaced by $20 \mathrm{~mL}$ of wort. The bottles were crowned, weighed, and shaken at $150 \mathrm{rpm}$ (Bühler GmbH SM30, Berlin, Germany) in a horizontal position for 3 days at room temperature $\left(25^{\circ} \mathrm{C}\right.$; Bühler $\mathrm{GmbH}$ TH30 incubator hoods, Berlin, Germany). After shaking, the bottles were left standing for $10 \mathrm{~min}$ and then manually turned upside down and right side up three times, with $10 \mathrm{~s}$ of standing between each turn. After the last turn and $30 \mathrm{~s}$ of standing, the bottles were opened. Once overfoaming ended, the bottles were weighed to determine the amount of overfoaming that occurred (Garbe et al., 2007; Rath, 2008; Deckers et al., 2011). Two bottles were prepared at least two times for each wort produced. 

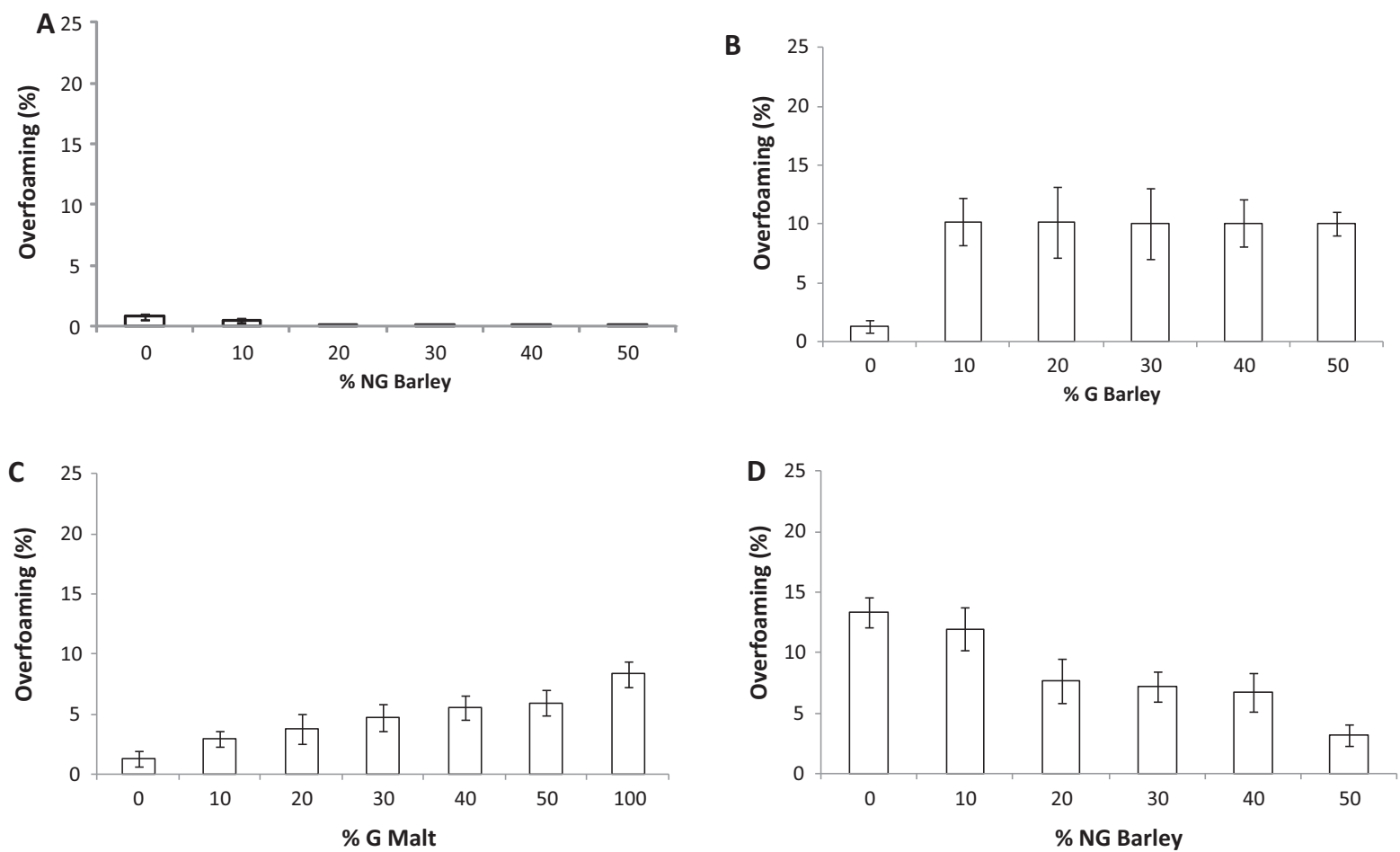

Fig. 1. Amount of overfoaming in the double modified Carlsberg Test provoked by extracts (worts) from combinations of gushing and non-gushing grains. (A) Wort produced with non-gushing barley and non-gushing malt; (B) wort produced with Gushing barley and non-gushing malt; (C) wort produced with non-gushing malt and Gushing malt and (D) wort produced with non-gushing barley and Gushing malt.

\section{Characterization of the gushing potential of barley and malt by the DLS (Dynamic Light Scattering) method}

After the gushing test, $20 \mathrm{~mL}$ of the overfoams were mixed with $30 \mathrm{~mL}$ of the remaining beverages and centrifuged (Beckman $\mathrm{J} 2-21$ ) at $4000 \times \mathrm{g}$ for $10 \mathrm{~min}$ at room temperature. When there was no overfoaming $50 \mathrm{~mL}$ of the beverages were used. The samples were then left to degas naturally in a separatory funnel, until the $\mathrm{CO}_{2}$ equilibrium concentration at atmospheric pressure $(1.66 \mathrm{~g} / \mathrm{L})$ was reached. The centrifuged and degassed samples $(45 \mathrm{~mL})$ were collected and the upper phase $(5 \mathrm{~mL})$ was transferred to the measurement cell (four optical sides), and the particle size was determined by DLS with a particle size analyzer (90Plus, Brookhaven Instruments Corp.). Five 1-min measurements were performed on each sample. The results were analyzed as described by Deckers et al. (2011).

\section{Results}

Fig. 1 shows the overfoams (in \% of the bottle content) after the gushing test. Overfoamings were observed only when a gushing raw material (barley or malt) was present in the grist. To confirm that the gushing is due to primary gushing, meaning that it is due to hydrophobins and that the potential to develop gushing of beer is high a DLS analysis was started. As it was shown by Deckers et al. (2011), gushings induced by hydrophobins are characterized by the formation of particles with a diameter of approximately $100 \mathrm{~nm}$ which correspond to gaseous $\mathrm{CO}_{2}$ nanobubbles stabilized by hydrophobins at atmospheric pressure. Fig. 2 shows the particle size distribution of the different worts after the gushing test. Particles with a diameter of approximately $100 \mathrm{~nm}$ were only detected in the samples containing contaminated raw material and showing overfoaming.

\section{Discussion}

It is known that diverse microbial communities naturally colonize barley grains (Noots et al., 1998; Laitila, 2007). Primary gushing is associated with malt prepared from barley at late-harvest times and in wetter seasons and is directly corresponding to the growth of microorganism on the barley kernels under moist conditions (Flannigan et al., 1982; Flannigan, 2003). The microbial communities of malted barley products assemble on the field, under storage and during the processing (Laitila, 2007). In general, filamentous fungi are divided into two groups; field and storage fungi (Noots et al., 1998). Field fungi such as Fusarium and Alternaria invade the seeds and occur outside/inside the grains until harvesting. They are more prevalent when rainfall is more than usual during grain fill and harvest. In the field, barley kernels are already colonized by microbes immediately after ear emergence from the enveloping leaf-sheaths (Flannigan, 2003) and continues throughout the growing season (Noots et al., 1998). At later stages of kernel filling, microbial colonization is restricted to the outer parts of the developing kernels, between the testa and the outer epidermidis. Occasionally, invasion of the endosperm is caused by fungi with distinct phytopathogenic characteristics, such as Fusarium fungi, or if the testa is for some reason injured (Laitila, 2007). If grain is stored at the proper moisture content and temperature, field fungi have insignificant influences, as they do not grow below a water activity of 0.90 (Noots et al., 1998). Storage fungi such as Aspergillus and Penicillium are habitually present in dust and air of the storage environment and can also be found in different farm and malting equipments (Laitila, 2007). They invade grains or seeds during storage but are usually not present in any serious extent before harvest. Small quantity of spores of storage fungi may be present on grain going into storage or may be present on spilled grain present in harvest, handling and storage equipment or structures. Under non appropriate storage conditions this low degree of infection increases rapidly leading to significant problems. Although the 

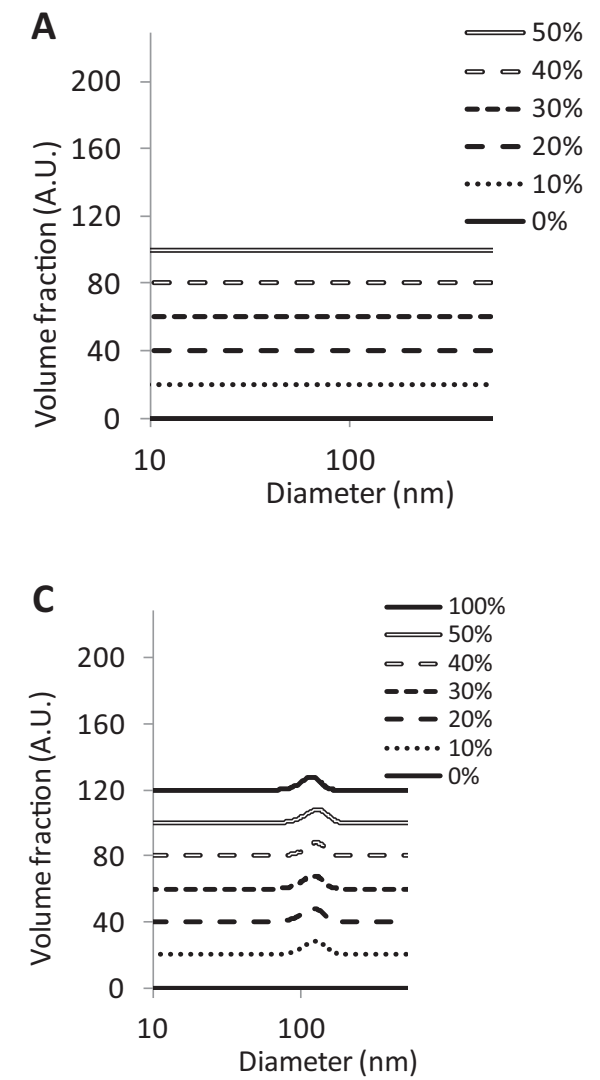
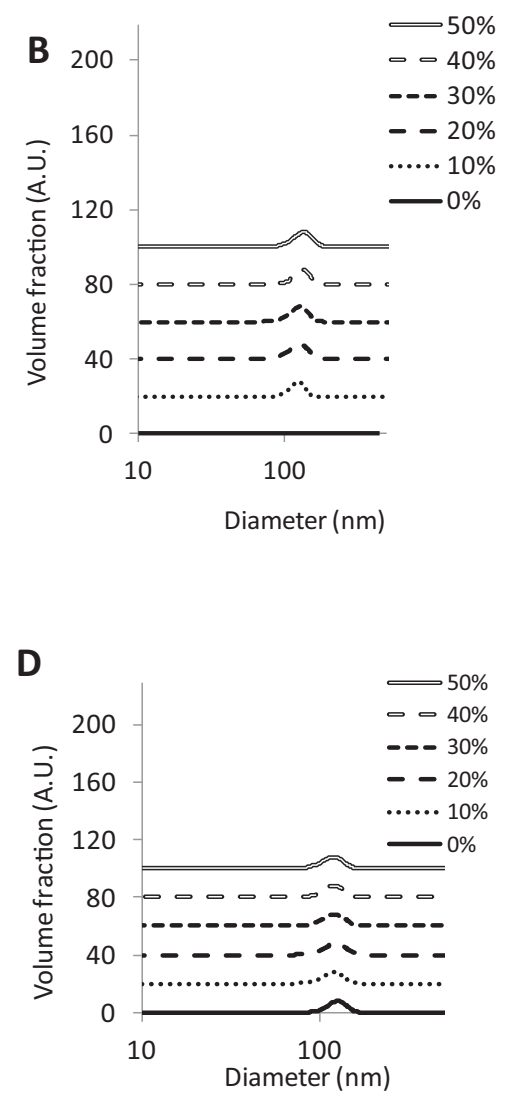

Fig. 2. Particle size distribution (detection of particles with $100 \mathrm{~nm}$ diameter) of the different worts after the doubly Modified Carlsberg Test. (A) Wort produced with non-gushing barley and non-gushing malt; (B) wort produced with Gushing barley and non-gushing malt; (C) wort produced with non-gushing malt and Gushing malt and (D) wort produced with non-gushing barley and Gushing malt. The percentages are mentioned in Table 1.

vegetative forms of molds progressively die with storage time, the spores on the grain remain viable and can be activated during the malting process under better conditions (Flannigan et al., 1982; Noots et al., 1998). This contamination of grains is not without any consequence as hydrophobins, a small surface-active proteins produced by these molds (Wessels, 1994, 1996), were tackled as the major contaminant which causes primary gushing (Haikara et al., 1999). It was showed that hydrophobins were present in the F. culmorum infected heads three weeks after inoculation and the formation of hydrophobins continued throughout the growing period (Sarlin et al., 2007). Sarlin et al. (2007) showed that although fungi produce hydrophobins which accumulate during barley grain development in the field, the production is more pronounced during malting. Malting conditions are highly favorable for microbial growth in terms of available nutrients, temperature, moisture content and gaseous atmosphere (Laitila, 2007). Fusarium fungi are able to proliferate and to produce hydrophobins during the malting process especially during the steeping and germination steps. Over 10-fold higher amounts of hydrophobins were found in malt, compared to those in the corresponding barley (Sarlin et al., 2007). These hydrophobins are able to form and stabilize $\mathrm{CO}_{2}$ nanobubbles which are responsible for primary gushing (Deckers et al., 2010, in press). These considerations about the contamination of grains by molds and the production of hydrophobins by these molds justify the fact that harvested barley and malt were chosen as raw material to be analyzed in order to see if it is possible to predict the primary gushing potential from the raw materials.

Presently there is no universal method to predict primary gushing of beverages. The gushing test seems to be the most used in practice although a lack of reproductibility between laboratory (Rath, 2008) and even within a same laboratory was underlined.
Recently it was shown that particle size analysis by DLS technique is a useful tool to analyze gushing (Nüter and Harms, 2009; Christian et al., 2009b; Deckers et al., 2011). Also the detection by DLS method of particles at $100 \mathrm{~nm}$ diameter corresponding to $\mathrm{CO}_{2}$ nanobubbles stabilized by hydrophobin ascertains that hydrophobins are involved in the gushing phenomenon and that the phenomenon is not a secondary gushing due to brewing parameters. However this method was described for gushing characterization of bottled carbonated beverages (Deckers et al., 2011). This explains why the method described here was developed on harvested barley and malt in order to see if this method could be applicable on raw materials.

In this study the combination of the doubly MCT and the DLS method was carried out for the first time. The Congress mash method was used to extract hydrophobins from the grains to standardize as much as possible the experimental parameters (Rath, 2008). According to Garbe et al. (2007), in the doubly MCT method only the fine grist was retained as it showed the most reliable results. To analyze harvested barley (gushing and non-gushing), the grist was mixed with the grist coming from non-gushing malt in order to produce a wort without any problem of filtration. Filtration problems occur if barley is used without using external enzyme due to the barley starch gelatinization at approx. $63^{\circ} \mathrm{C}$ (Briggs et al., 2004). Grist from gushing and non-gushing malt samples were mixed together in order to obtain different level of contamination. As carbon dioxide is a prerequisite to gushing (Pellaud, 2002; Deckers et al., 2011) and as the DLS method is based on the detection of $\mathrm{CO}_{2}$ nanobubbles stabilized by hydrophobins, the wort obtained was diluted into sparkling water in order to make the contact between hydrophobin and gaseous $\mathrm{CO}_{2}$. The DLS analysis and the detection of particles with a diameter of approximately 
$100 \mathrm{~nm}$ were used to confirm the presence of hydrophobins in the wort obtained from the grains analyzed (Deckers et al., 2011). For the samples tested, only $5 \%$ of contaminated grains was enough to induce gushing and to form stabilized nanobubbles detected by DLS. The results obtained here show that a predictive method to analyze barley and malt samples concerning the possibility of primary gushing is reported and show also that it is possible to predict the primary gushing potential at raw material level. However, malting and brewing process vary between different malt houses and breweries which may have an influence on the production and the fate of hydrophobin. As showed by Sarlin et al. (2007), the amount of hydrophobins is increased during malting process, but decreased during brewing (only about $10 \%$ of the hydrophobin present in the malt was found in the final beer). It has to be emphasized that a minimal concentration of hydrophobin is necessary to induce gushing (Sarlin et al., 2005). In other words, a non-gushing barley may become a gushing malt due to the increase of hydrophobin concentration during the malting process and that a gushing malt may result in a non-gushing beer due to the reduction of hydrophobin concentration during the brewing process.

\section{Acknowledgments}

This research was supported by the KU Leuven-University Foundation-Hydrophobin grant by the Duvel-Moortgat, Orval, and Chimay breweries and Cargill Malting. We thanked Dingemans Mouterij and Cargill Malting for the delivery of barley and malt samples, respectively. Boortmalt is thanked for equipment and Spadel S.A. for the production of the sparkling water.

\section{References}

Briggs, D.E., Boulton, C.A., Brookes, P.A., Stevens, R., 2004. Brewing Science and Practice. CRC Press LLC, Boca Raton.

Casey, G.P., 1996. Primary versus secondary gushing and assay procedures used to assess malt/beer gushing potential. MBAA Technical Quarterly 33 (4), 229-235.

Christian, M., Ilberg, V., Titze, J., Parlar, H., Jacob, F., 2009a. New ideas for quantifying the gushing potential of malt. Brewing Science 62, 164-170.

Christian, M., Ilberg, V., Aydin, A.A., Titze, J., Friess, A., Jacob, F., Parlar, H., 2009b. New gushing mechanism proposed by applying particle size analysis and several surfactants. Brewing Science 62 (07/08), 100-107.

Christian, M., Titze, J., Ilberg, V., Jacob, F., 2010a. Combined particle analysis as a new tool to predict gushing shown with alcohol-free beverages products. Brewing Science 63, 72-75.

Christian, M., Titze, J., Ilberg, V., Jacob, F., 2010b. New cognitions on gushing in the wort production process and in quantifying the gushing potential of malt. Cerevisia Belgian Journal of Brewing and Biotechnology 35, 35-37.

Christian, M., Titze, J., Ilberg, V., Jacob, F., 2011. Novel perspectives in gushing analysis: a review. Journal of the Institute of Brewing 117 (3), 295-313.

Deckers, S.M., Gebruers, K., Baggerman, G., Lorgouilloux, Y., Delcour, J.A., Michiels, C., Derdelinckx, G., Martens, J., Neven, H., 2010. $\mathrm{CO}_{2}$-hydrophobin structures acting as nanobombs in beer. Part 1: A critical review of hypotheses and mechanisms. Brewing Science 63, 54-61.

Deckers, S.M., Lorgouilloux, Y., Gebruers, K., Baggerman, G., Verachtert, H., Neven, H., Michiels, C., Derdelinckx, G., Delcour, J.A., Martens, J., 2011. Dynamic Light Scattering (DLS) as a tool to detect $\mathrm{CO}_{2}$-hydrophobin structures and study the primary gushing potential of beer. Journal of the American Society of Brewing Chemists 69 (3), 144-149.
Deckers, S.M., Venken, T., Khalesi, M., Gebruers, K., Baggerman, G., Lorgouilloux, Y., Shokribousjein, Z., Ilberg, V., Schönberger, C., Titze, J., Verachtert, H., Michiels, C., Neven, H., Delcour, J., Martens, J., Derdelinckx, G., De Maeyer, M., 2012. J. Am. Soc. Brew. Chem., in press.

European Brewing Convention, 2004. Analytica-EBC, Section 4, Method 4.5.1 Extract of Malt: Congress Mash. Verlag Hans Carl Getränke-Fachverlag, Nürnberg, Germany.

Fischer, S., 2001. Blasenbildung von in flüssigkeiten gelösten gasen. Dissertation. Technische Universität München.

Flannigan, B., 2003. The microbiota of barley and malt. In: Priest, F.G., Campell, I. (Eds.), Brewing Microbiology. , 3rd ed. Kluwer Academic/Plenum Publishers, New York.

Flannigan, B., Okague, R.N., Khalid, R., Teoh, C.K., 1982. Mould flora of malt in production and storage. Brewing \& Distilling International 12, 31-37.

Garbe, L.-A., Nagel, R., Rauschmann, M., Lamers, M., Ehmer, A., Tressl, R., 2007. Correlation of deoxynivalenol, hydrophobins and gushing. In: Proc. Eur. Brew. Conv. Congr., Venice.

Garbe, L.-A., Schwarz, P., Ehmer, A., 2009. Beer gushing. In: Bamforth, C.W., Russell, I., Stewart, G.G.(Eds.), Beer: A Quality Perspective. Elsevier, New York, pp. 185-212.

Gardner, R.J., 1973. The mechanism of gushing - a review. Journal of the Institute of Brewing 79, 275-283.

Haikara, A., Sarlin, T., Home, S., 2005. Determination of gushing tendency of malt. Journal of the Institute of Brewing 111 (2), 247.

Haikara, A., Sarlin, T., Nakari-Setälä, T., Penttilä, M., 1999. Method for determining a gushing factor for a beverage. Internat. Patent Appl., WO 99/54725.

Hunter, R.J., 2005. Chapter V: particle size and shape. In: Foundations of Colloid Science, 2nd ed. Oxford University Press Inc., New York.

Kastner, H., 1909. Das “Wildwerden” des Malzbieres. Wochenschrift für Brauerei 26, 169-170.

Laitila, A., 2007. Microbes in tailoring of barley properties. Dissertation. University of Helsinki.

Nelson, C.E., 2009. Conditions for bubble formation in porous regions and narrow channels. http://www.nelsonresearchinc.com/WorkBubbles/Bubble\% 20Formation\%20in\%20Porrous\%Regions.ppt. Nelson Research, Inc., Seattle (accessed 15.08.09).

Noots, I., Delcour, J.A., Michiels, C.W., 1998. From field barley to malt: detection and specification of microbial activity for quality aspects. Critical Reviews in Microbiology 25 (2), 121-153.

Nüter, C., Harms, D., 2009. Particle measurement in beverages - a new tool for a statement on gushing. In: Abstract 32nd Congr. Eur. Brew. Conv., Hamburg, Germany.

Pellaud, J., 2002. Gushing: state of the art. Cerevisia Belgian Journal of Brewing and Biotechnology 27 (4), 189-205.

Rath, F., 2008. Investigations to Improve the Reproducibility of the "Modified Carlsberg Test". The Gushing Day, Brussels.

Sarlin, T., Nakari-Setälä, T., Linder, M., Penttilä, M., Haikara, A., 2005. Fungal hydrophobins as predictors of the gushing activity of malt. Journal of the Institute of Brewing 111 (2), 105-111.

Sarlin, T., Vilpola, A., Kotaviita, E., Olkku, J., Haikara, A., 2007. Fungal hydrophobins in the barley-to-beer chain. Journal of the Institute of Brewing $113(2), 147-153$.

Shokribousjein, Z Deckers, S.M. Gebruers, K, Lorgouilloux, Y, Baggerman, G, Verachtert, H., Delcour, J.A., Etienne, P., Rock, J.-M., Michiels, C., Derdelinckx, G., 2011. Hydrophobins, beer foaming and gushing. Cerevisia Belgian Journal of Brewing and Biotechnology 35, 85-101.

Wessels, J.G.H., 1994. Developmental regulation of fungal cell-wall formation. Annual Review of Phytopathology 32, 413-437.

Wessels, J.G.H., 1996. Fungal hydrophobins: proteins that function at an interface. Trends in Plant Science 1, 9-15.

Wessels, J.G., de Vries, O.M., Asgeirsdottir, S.A., Springer, J., 1991. The thn mutation of Schizophyllum commune, which suppresses formation of aerial hyphae, affects expression of the Sc3 hydrophobin gene. Journal of General Microbiology 137, 2439-2445.

Wilson, S.M., Le Maguer, M., Duitschaever, C., Buteau, C., 1999. Gushing ciders: sediment characteristics and bubble generation. In: Poster Presented at the "Food Science at Work" Meeting, Guelph University, Canada.

Winkelmann, L., Hinzmann, E., 2009. The gushing-puzzle - parts are still missing. Brauwelt International 27 (1), 13-15.

Zoecklein, B., 1999. A review of méthode champenoise production. Virginia Polytechnic Institute and State University, USA. Publication number 463-017. 